\title{
Factors Contributing to Alcoholism Among the Youth in New Edubiase of Adansi South District in Ashanti Region-Ghana
}

\section{*Christiana Asiedu, Augustine Darkwa Opoku, James Abankro, Jameela Bint Entsie}

Department of Adult Health, School of Nursing and Midwifery, College of Health and Allied Science, University of Cape Coast-Ghana.

\section{ABSTRACT}

The future of every nation lies in the hands of the youth who are expected to be strong and healthy. Most youths put their future into jeopardy by indulging in risky health habits, particularly alcoholism. The purpose of this study was to find out the factors contributing to Alcoholism among the youth in New Edubiase. The study was quantitative with a descriptive cross-sectional design. The study population was a youth in New Edubiase. A multi-stage sampling technique was used to select a sample size of 350. A questionnaire was used for collecting the data. The results were presented in frequencies, percentages and chi-square test. The study found out that the use of alcohol among the youth was low as most of them were uncertain of taking alcoholic beverages. Again, there was high knowledge about alcohol use and its implication on the health of abusers. Further, interventions for alcohol use include punishment of alcohol abusers, enforcement of laws on sales of alcoholic products and the prohibition of an advertisement on alcohol before 9:00 pm. In conclusion, the high knowledge of the youth about alcoholic products and the effect of the health of alcohol abusers could be due to the effort of a health care professional in educating the masses about the health implication. It was recommended that the Food and Drugs Authority must ensure that all media houses adhere to the new directive on the ban of advertisements on alcoholic beverages before 9:00 pm.

Keywords: Abuse, Alcoholism, Economic, Risky Behavior, Youth, New Edubiase

\section{Introduction}

Alcohol abuse is associated with public health and socio-economic development burdens. Some youth who abuse alcohol may engage themselves in criminal activities and face school failure. Worldwide and in Ghana, alcohol is the only psychotropic substance most widely used by the youth [1,2]. Alcohol use by the youth is a considerable health problem because it contributes to the leading causes of youth morbidity and mortality [1,3].In 2011, the World Health Organization (WHO) reported that nine percent of annual deaths of youth between the ages of 15 to 25 years were attributed to alcoholrelated causes [4]. Alcohol is implicated in relationship breakdown, decreased academic achievement, depression, other substance use, unintentional injuries, serious road traffic accidents, domestic violence, liver cirrhosis, cancers, poor parenting, child neglect and abuse $[1,5]$.

Family members of people who are alcohol dependent have a high rate of psychiatric morbidity, and growing up with someone who 
misuses alcohol increases the likelihood of teenagers taking up alcohol early and developing alcohol problems themselves [1,6]. Although the minimal drink age is 21 years in Ghana, some begin in childhood. This may continue to rocket into late adolescence and beyond [7]. Lifestyle, access to alcohol advertisement, high level of stressful situations coupled with anxiety, low selfesteem of an individual, depression, peer pressure susceptibility, and other problems related to education were considered as facilitators of alcohol consumption among the youth [1.8].

Illicit alcohol use increases the public health problem in Ghana $[1,9,10]$ with an estimation that $40 \%$ of the youth may be abusing alcohol [10]. This affirms a widespread agreement that the health and well-being of many young people today are seriously being threatened by the use of alcohol. These youth are expected to be strong and healthy enough to contribute effectively to the socio-economic growth and development. However, most in this productive age group indulge in risky health habits, particularly alcoholism thereby putting their future into jeopardy [11]. Emerging trends in alcohol consumption have permeated the youth culture, showing increasing signs of surpassing national boundaries. There appears to be an international pattern towards a more hedonistic attitude to drinking, consciously using alcohol for its pleasurable psychological effects [12]. The effects of alcohol abuse ultimately cause poor academic performance and intend to affect the complete future of an adult. Loss of employment, drunk driving or public disorders, tortuous behavior, marital conflicts, divorce or domestic violence are some forms of social effects seen among the alcoholic youth [13].

The WHO estimates that there are about 2 billion people worldwide who consume alcoholic beverages and 76.3 million with diagnosable alcohol use disorders. This estimate has it that, nearly 62 million people out of this number are alcohol dependent. The prevalence of the illness, however, varies in different countries [14]. It is estimated that $89 \%$ of Ghanaian youth will become drinkers unless they are given the education to change the situation [15]. A study conducted on the pattern and prevalence of alcohol-impaired driving in Ghana using a random breathalyzer survey of drivers found that $21 \%$ of the drivers who were tested had detectable blood alcohol concentrations [16]. A qualitative study carried out in the Upper West Region of Ghana on the consumption and impact of a locally made alcohol (Akpeteshie) found strong perceptions of the health and economic damage that alcohol is having on the people of the area [17]. The situation in New Edubiase of the Adansi South District may not be different. The study was conducted to investigate the factors responsible for the upsurge in alcoholism among the youth in the New Edubiase of Adansi South District.

\section{Research Objectives}

1. To determine the level of alcohol use

2. To assess the level of knowledge of the youth about alcohol.

3. To determine the types of alcohol use among the youth.

4. To determine the predisposing factors for alcoholism among the youth.

5. To assess the consequences of alcohol abuse among the youth.

6. To determine interventions on alcohol use.

\section{Materials and Methods}

\section{Research Design}

The study was a cross-sectional study in which the variables under study are measured at a specific point in time for a defined population. This type of data can be used to assess the 
prevalence of conditions in the target population. This design enabled the researchers to gather a large data about the respondents in a relatively lesser time and at a lower cost. However, the study design is limited in the sense that it only provides a snapshot of analysis so there is always the possibility that a study could have differing results if another time-frame had been chosen. Also, the study findings cannot be utilized to establish cause and effect relationships.

\section{Study Area}

The study was conducted in New Edubiase in the Adansi South District of the Ashanti region. New Edubiase is the capital of Adansi south district and it shares boundaries with Atobiase in the south, Amudurase in the north, Menang in the west and Bronikrom in the east. The estimated population of New Edubiaseis 37, 500 with 8,175 as a youth. The youth in New Edubiaseare mainly farmers, traders, palm wine tappers, students, tailoring, and hairdressing with a small fraction doing white-collar jobs.

\section{Population}

The study population comprised the youth between 15-35 years who reside in New Edubiase of the Adansi South District. The youthful population for both males and females in New Edubiase are estimated to be 8,175 , representing $21.8 \%$ of the total population $(37,500)$. Language spoken includes Asante Twi, Fante, Ewe, Frafra, Wala and Dagaare. A valid sample of 355 youth out of the 8,175 youth population was considered for the study. The study included youth in the Senior High School (SHS) and both employed and unemployed youth in the study area.

\section{Sampling Procedure}

The study utilized a sample size of 355 based on a confidence level of $95 \%$ and $5 \%$ of margin of error, using the Cochran's formula for calculating sample size and taking into account the nonresponses as follows:

$n=\frac{Z^{2} p q(1-p)}{E^{2}}$, assuming 30\% prevalence.

Where $\mathrm{n}=$ the desired sample size

$\mathrm{E}=$ margin of error at $5 \%=0.05$

$\mathrm{Z}=$ Confidence interval (Cl) of $95 \%=1.96$

$\mathrm{P}=$ the estimated proportion who abuse alcohol = 0.30

$\mathrm{q}=(1-\mathrm{p})=$ the proportion who do not abuse alcohol $=(1-0.30)=0.70$

Therefore;

$\mathrm{n}=\underline{1.96^{2}(0.30 * 0.70)}$

$(0.05)^{2}$

$\mathrm{n}=\underline{3.8416(0.21)}$

0.0025

$\mathrm{n}=\underline{0.806736}$

0.0025

$\mathrm{n}=322.6$

$\mathrm{n}=323$

Assuming 10\% non-response $=32$

$\mathrm{n}=323+32=355$

Two multi-stage sampling methods were used to select participants. A list of all the houses in New Edubiase was obtained from the planning department in the Adansi South Assembly. A simple random sampling technique was used to select the first house and systematic sampling was employed to select every 5 th house until all the 355 houses were selected. In houses where there was more than one household, simple random sampling was used to select one. This was done by balloting YES or NO and the household that picked YES was chosen for the study. In households where there were more eligible participants, again simple random sampling was used to select one respondent. This was done through balloting, 
YES or NO and an individual who picked YES was chosen for the study. This procedure was repeated until the total sample size was obtained.

\section{Data Collections Instrument}

The study employed a quantitative approach to data collection. The measurement tool for the study was a self-administered questionnaire, available in the English language. The questions were open-ended and close-ended. It included questions related to age, sex, religion, marital status, level of alcohol use, knowledge on alcohol, types of alcohol, predisposing factors, effects of alcohol abuse and interventions. The instrument was adapted from previous studies because it had similar attributes or characteristics to this study $[1,18]$. The data collection instrument was modified to suite the variables of the study. The questionnaire consisted of seven (7) sections. Section A was made up of the background characteristics of the respondents. Section B dealt with the levels of alcohol use. Section C comprised of knowledge of the youth about alcohol. The type of alcoholic beverages was found in section D. section $\mathrm{E}$ focused on the predisposing factors influencing alcohol use among the youth whereas sections $\mathrm{F}$ and $\mathrm{G}$ contained the consequences of alcoholism and interventions respectively. Even though the questionnaire might have some setbacks such as misunderstanding or misinterpretation of questions, limited choice of responses and time-consuming to collect the data, it was economical, standardized, easily replicated to check for reliability and provided quantitative data for relatively easy analyzes.

The questionnaire for the study was pre-tested in Atobiase Township. The town shares some similar characteristics and environment as New Edubiase. Points noted and assessed during the pretest included the availability of the sample needed for the full study, the desire of the youth to participate, clarity of the language used and time needed for administering the questionnaire. Based on feedback from the pre-test, the questionnaire was modified to ensure its clarity and suitability to the study.

\section{Data Processing and Analysis}

Data from the questionnaire was cross-checked, entered and analyzed using the Statistical Package for the Social Sciences (SPSS) version 21. Data cleaning was done and generated results from the analysis were presented as frequencies and percentages.

\section{Ethical Consideration}

Permissions were obtained from the District Chief Executive, District Health Directorate, the assembly members, parents/ guardians, other opinion leaders and the youth before the commencement of the study. Confidentiality, privacy, and anonymity were also assured. The respondent's names were not asked, and thus the results of the data were not linked to any individual youth. The participating youth were briefed on the characteristics and purpose of the study and their right to withdraw at any point should they wish to do so. Informed consent in writing was obtained before the participants were involved in the survey. It included the purpose of the study, possible risk and discomfort, possible benefits, privacy, confidentiality, and voluntary participation. A participant who gave consent but later decided to withdraw was allowed to do so without hindrance or offence. Dates and time of day the data were collected, for how long and by whom was indicated. Any problem encountered in collecting the data was pointed out.

\section{Results}

Demographic Characteristics of Respondents

The demographic data of the respondents were 
taken and presented in table one (1). It was found out that the majority of the respondents, $32.3 \%$ (113), aged between 25 and 29 years with a mean and standard deviation of 3.15 and 1.196 respectively. Males formed the majority of the respondents, $51.4 \%$ (180) with a mean of 1.49 and a standard deviation of 0.501 , which indicates that deviation in the sex of the respondents centred on the mean. Again, the marital status of the respondents indicates that most of the respondents, $45.4 \%$ (159) were married with a mean of 1.82 and a standard deviation of 0.964 . Many of the respondents, $34.6 \%$ (121) were public servants with the mean and standard deviation of occupation found to be 2.33 and 1.224 respectively. Two hundred and thirty-one representing $66.0 \%$ were

\section{Table 1- Demographic Data of Respondents}

\begin{tabular}{|l|l|l|l|l|}
\hline Variable & Frequency & Percentage & Mean & S. Deviation \\
\hline Age & & & 3.15 & 1.196 \\
\hline $15-19$ & 31 & 8.9 & - & - \\
\hline $20-24$ & 75 & 21.4 & - & - \\
\hline $25-29$ & 113 & 32.3 & - & - \\
\hline $30-39$ & 72 & 20.6 & - & - \\
\hline$>35$ & 59 & 16.9 & - & - \\
\hline Sex & & & 1.49 & 0.501 \\
\hline Male & 180 & 51.4 & - & - \\
\hline Female & 170 & 48.6 & - & - \\
\hline Marital Status & & & 1.82 & 0.964 \\
\hline Married & 159 & 45.4 & - & - \\
\hline Single & 129 & 36.9 & - & - \\
\hline Co-habiting & 37 & 10.6 & - & - \\
\hline Divorce & 17 & 4.9 & - & - \\
\hline Widow & 8 & 2.3 & - & - \\
\hline Table 1 cont'd & & & - & - \\
\hline Occupation & - & - & - & - \\
\hline Public servant & 121 & 34.6 & - & - \\
\hline Self-employed & 82 & 23.4 & -224 \\
\hline Unemployed & 73 & 20.9 & - & - \\
\hline Farming & 60 & 17.1 & - & - \\
\hline Others & 14 & 4.0 & - & - \\
\hline Religion & & & - & \\
\hline & & & - & - \\
\hline
\end{tabular}




\begin{tabular}{|l|l|l|l|l|}
\hline Christian & 231 & 66.0 & - & - \\
\hline Muslim & 64 & 18.3 & - & - \\
\hline Traditional & 15 & 4.3 & - & - \\
\hline No Religion & 40 & 11.4 & - & - \\
\hline Ethnicity & & & 2.56 & 1.185 \\
\hline Ga & 55 & 15.7 & - & - \\
\hline Akan & 150 & 42.9 & - & - \\
\hline Ewe & 78 & 22.3 & - & - \\
\hline Dagaati & 27 & 7.7 & - & - \\
\hline Others & 40 & 11.4 & - & - \\
\hline
\end{tabular}

Christians; the mean and standard deviation recorded for the religious denomination of the respondents being 1.61 and 1.006 respectively. Akans formed majority of the respondents, $42.9 \%$ (150), with a mean of 2.56 and a standard deviation of 1.185 recorded for the ethnic origin of the respondents.

\section{Levels of Alcohol Use}

Many of the respondents, $47.4 \%$ (166) were undecided whether they drink at night. A mean of 2.02 indicates that most of the respondents were undecided and strongly disagreed to the statement that they drink at night, which had a standard deviation of 1.213. Most, 48.6\% (170) were undecided that they drink alcohol in the afternoon, mean $=1.93$ and standard deviation $=$ 1.129. One hundred and eighty representing 51.4\% were also undecided that they drink in the morning with mean of 1.84 and standard deviation of 1.059 .
Majority of them, 48.0\% (168), were also uncertain about the statement that they drank alcohol a day prior to the study with a mean of 2.02 and a standard deviation of 1.229. Again, with a mean of 2.04 and a standard deviation of 1.216, many of the respondents were uncertain about the statement that they drank alcohol a week prior to the study. Also, 45.4\% (159) were uncertain that they took alcohol two weeks prior to the study with a mean of 1.97 and a standard deviation of 1.114. One hundred and fifty-one representing $43.1 \%$ of the respondents were uncertain that drank alcohol about a month before the study was conducted. More so, 42.9\% (150) were uncertain that they took in alcohol about three months preceding the conduction of this study. One hundred and seventeen representing $33.4 \%$ also were uncertain that they took alcohol about a year before the study. Ninety-two representing $26.3 \%$ of the respondents were. 


\section{Table 2- Levels of Alcohol Use}

\begin{tabular}{|c|c|c|c|c|c|c|c|}
\hline \multicolumn{8}{|c|}{ Frequency (Percentage) } \\
\hline Variable & $\mathbf{U}$ & SD & D & A & SA & Mean & S. Dev \\
\hline Only drink at night & $166(47.4)$ & $79(22.6)$ & $54(15.4)$ & $33(9.4)$ & $18(5.1)$ & 2.02 & 1.213 \\
\hline Drink in the afternoon & $170(48.6)$ & $88(25.1)$ & $52(14.9)$ & $27(7.7)$ & $13(3.7)$ & 1.93 & 1.129 \\
\hline Drink in the morning & $180(51.4)$ & $86(24.6)$ & $52(14.9)$ & $24(6.9)$ & $8(2.3)$ & 1.84 & 1.059 \\
\hline Took alcohol a day ago & $168(48.0)$ & $78(22.3)$ & $54(15.4)$ & $29(8.3)$ & $21(6.0)$ & 2.02 & 1.229 \\
\hline Took alcohol 1 week ago & $159(45.4)$ & $87(24.9)$ & $56(16.0)$ & $26(7.4)$ & $22(6.3)$ & 2.04 & 1.216 \\
\hline Took alcohol 2 weeks ag & $158(45.1)$ & $92(26.3)$ & $65(18.6)$ & $21(6.0)$ & $14(4.0)$ & 1.97 & 1.114 \\
\hline Took alcohol 1 month ag & $151(43.1)$ & $85(24.3)$ & $67(19.1)$ & $21(6.0)$ & $26(7.4)$ & 2.10 & 1.235 \\
\hline Took alcohol 3 months a & $150(42.9)$ & $92(26.3)$ & $62(17.7)$ & $21(6.0)$ & $25(7.1)$ & 2.08 & 1.219 \\
\hline Took alcohol 1 year ago & $117(33.4)$ & $78(22.3)$ & $94(26.9)$ & $30(8.6)$ & $31(8.9)$ & 2.37 & 1.269 \\
\hline Don't remember taking a & $92(26.3)$ & $72(20.6)$ & $60(17.1)$ & $43(12.3)$ & $83(23.7)$ & 2.87 & 1.522 \\
\hline Drink occasionally & $119(34.0)$ & $55(15.7)$ & $65(18.6)$ & $63(18.0)$ & $48(13.7)$ & 2.62 & 1.451 \\
\hline
\end{tabular}

Neutral to the statement that they could not remember taking alcohol. Lastly, $34.0 \%$ (119) were neutral to the statement that they drink occasionally.

\section{Knowledge about Alcohol Consumption}

The second research question sought to find out the knowledge of the youth about the consumption of alcohol. The findings of the study regarding this particular research question are presented in table 3. It was found out that many of the respondents, $43.1 \%$ (151), agreed that alcohol consumption causes brain damage with a mean of 4.15 and a standard deviation of 0.975. Majority of the respondents, $48.0 \%$ (168), also strongly agreed that alcohol consumption causes an increase in blood pressure with a mean of 4.22 and a standard deviation of 0.972 indicating a minimal deviation or variation from the mean. With a mean of 4.33 and a standard deviation of 0.889 , majority of the respondents strongly agreed that alcohol consumption causes liver diseases, $51.7 \%$ (181). It was strongly agreed by $52.9 \%$ (185) that alcohol consumption causes stomach ulcer with a mean of 4.30 and a standard deviation of 0.968 indicating a small deviation from the mean in terms of the responses. Majority of the respondents, $33.7 \%$ (118) with a mean of 3.75 and a standard deviation of 
Table 3- Knowledge about Alcohol Consumption

Frequency (Percentage)

\begin{tabular}{|l|l|l|l|l|l|c|c|}
\hline \multicolumn{1}{|c|}{ Variable } & U & SD & D & A & SA & Mean & S. Dev. \\
\hline Causes brain damage & $7(2.0)$ & $28(8.0)$ & $18(5.1)$ & $151(43.1)$ & $146(41.7)$ & 4.15 & 0.975 \\
\hline Increases blood pressure & $7(2.0)$ & $23(6.6)$ & $24(6.9)$ & $128(36.6)$ & $168(48.0)$ & 4.22 & 0.972 \\
\hline Causes liver diseases & $5(1.4)$ & $19(5.4)$ & $12(3.4)$ & $133(38.0)$ & $181(51.7)$ & 4.33 & 0.889 \\
\hline Causes stomach ulcer & $8(2.3)$ & $22(6.3)$ & $13(3.7)$ & $122(34.9)$ & $185(52.9)$ & 4.30 & 0.968 \\
\hline $\begin{array}{l}\text { Much intake can cause } \\
\text { epilepsy }\end{array}$ & $19(5.4)$ & $46(13.1)$ & $55(15.7)$ & $112(32.0)$ & $118(33.7)$ & 3.75 & 1.205 \\
\hline Cause forgetfulness & $13(3.7)$ & $36(10.3)$ & $19(5.4)$ & $112(32.0)$ & $170(48.6)$ & 4.11 & 1.130 \\
\hline
\end{tabular}

1.205, strongly agreed that much alcohol intake can cause epilepsy. Lastly, most of the respondents, 170 representing $48.6 \%$ with a mean of 4.11 and a standard deviation of 1.130 , strongly agreed that alcohol intake causes forgetfulness.

\section{Types of Alcoholic Beverages}

The third research question sought to find out the types of alcoholic beverages that the respondents who reported of drinking alcohol drink most. It was found out that beer was the most drank alcoholic beverage, which was reported among $17.7 \%$ (62) with a mean of 4.64 and a standard deviation of 2.626 as presented in table 4 .

Table 4- Types of Alcohol Beverages

\begin{tabular}{|l|c|l|l|l|}
\hline Variable & Frequency & Percentage & Mean & S. Deviation \\
\hline Akpeteshi & 46 & 13.1 & 4.64 & 2.626 \\
\hline Beer & 62 & 17.7 & - & - \\
\hline Bitters & 27 & 7.7 & & - \\
\hline Palm wine & 60 & 17.1 & - & - \\
\hline Gin & 14 & 4.0 & & \\
\hline Guinness & 22 & 6.3 & - & - \\
\hline Wine & 26 & 7.4 & & \\
\hline None & 89 & 25.4 & - & - \\
\hline Others & 4 & 1.1 & - & - \\
\hline
\end{tabular}




\section{Factors Influencing Alcohol Use}

The fourth research question sought to find out some of the factors that influence the youth to use alcoholic products. The findings presented in table 5 indicated that majority of those who reported to have been influenced to use alcohol, 23.1\% (81) with a mean of 4.91 and a standard deviation of 3.030, mentioned peer pressure as an influence. Television was the major source of information on alcoholic products, which was reported by $56.3 \%$ (197) with a mean response of 1.57 and a standard deviation of 0.869. Many of the respondents, $56.0 \%$ (196) reported that advertisements on alcoholic products do not encourage them to use them.

\section{Table 5- Factors Influencing Alcohol Use}

\begin{tabular}{|c|c|c|c|c|}
\hline Variable & Frequency & Percentage & Mean & S. Deviation \\
\hline Influence & - & - & 4.91 & 3.030 \\
\hline Peer pressure & 81 & 23.1 & - & - \\
\hline Advertisement & 51 & 14.6 & - & - \\
\hline Social media & 15 & 4.3 & - & - \\
\hline Parental/sibling influence & 12 & 3.4 & - & - \\
\hline Availability/accessibility & 10 & 2.9 & - & - \\
\hline To get rid of problems & 10 & 2.9 & - & - \\
\hline Pleasure/just to have fun & 34 & 9.7 & - & - \\
\hline None & 137 & 39.1 & - & - \\
\hline Source of information & - & - & 1.57 & 0.869 \\
\hline Television & 197 & 56.3 & - & - \\
\hline Radio & 135 & 38.6 & - & \\
\hline Billboards & 2 & 0.6 & - & - \\
\hline Magazines & 7 & 2.0 & - & - \\
\hline Mobile phone & 6 & 1.7 & - & - \\
\hline Others & 3 & 0.9 & - & - \\
\hline Table 5 cont'd. & - & - & - & - \\
\hline Advert encourage use & - & - & 1.56 & 0.497 \\
\hline- & - & - & - & - \\
\hline Yes & 154 & 44.0 & - & - \\
\hline
\end{tabular}




\begin{tabular}{|l|l|l|l|l|}
\hline No & 196 & 56.0 & - & - \\
\hline Aspects of advertisements & - & - & 2.31 & 1.339 \\
\hline Use of celebrities & 104 & 29.7 & - & - \\
\hline Musical & 157 & 44.9 & - & - \\
\hline Animation & 10 & 2.9 & - & - \\
\hline Role models & 33 & 9.4 & - & - \\
\hline Others & 46 & 13.1 & - & - \\
\hline Cultural norms allow use & - & - & 1.46 & 0.499 \\
\hline Yes & 190 & 54.3 & - & - \\
\hline No & 160 & 45.7 & - & - \\
\hline Regulations on alcohol & - & - & 1.34 & 0.474 \\
\hline Yes & 231 & 66.0 & - & - \\
\hline No & 119 & 34.0 & - & - \\
\hline Reasons for drinking & - & - & 1.84 & 0.742 \\
\hline Feel sad/depressed & 118 & 33.7 & - & - \\
\hline Have good time at party & 179 & 51.1 & - & - \\
\hline $\begin{array}{l}\text { I want to be accepted } \\
\text { by friends }\end{array}$ & 43 & 12.3 & - & - \\
\hline authorities & 10 & 2.9 & - & \\
\hline
\end{tabular}

One hundred and fifty-seven representing $44.9 \%$ of the respondents asserted that they could be influenced by the musical aspect of advertisements on alcoholic beverages to use them. However, it was reported by $54.3 \%$ (190) with a mean and a standard deviation of 0.499 that cultural norms allow for the use of alcoholic beverages. Many of the respondents, 66.0\% (231) asserted that are regulations on the use of alcohol. The major reason for drinking alcohol by most of the respondents, $51.1 \%$ (179), is that they want to have a good time at the party; a reported mean and standard deviation of 1.84 and 0.742 respectively.

\section{Consequences of Alcoholism}

The findings of the study on the consequences of alcoholism as presented in table 6 revealed that majority of them, 53.1\% (186) were uncertain that they had ever been suspended from school due to the use of alcohol. Also, many of the respondents, 51.7\% (181) were uncertain that they had ever had motor accidents due to alcohol drinking. Again, many, 35.7\% (125) were uncertain that they had ever fought 
with a friend due to the use of alcohol. Also, 34.0\% (119) of the respondents were uncertain whether they had ever used bad language on other people under the influence of alcohol. One hundred and twenty-five representing $35.7 \%$ were uncertain that they had ever had sexual temptations due to the use of alcohol. Most of the respondents, 39.1\% (137), we're uncertain that they had ever performed poorly in school due to the use of alcohol. A majority, 35.1\% (123) were uncertain that they had ever fallen sick due to the abuse of alcohol. Again, 34.9\% (122) were uncertain that they had ever been absent from school or work due to alcohol intake. Again, 37.4\% (131) were uncertain that they had ever skipped lessons in school as a result of being under the influence of alcohol. Lastly, 39.7\% (139) were also uncertain that they had ever been punished due to alcohol intake.

\section{Table 6- Consequences of Alcoholism}

\section{Frequency (Percentage)}

\begin{tabular}{|c|c|c|c|c|c|c|c|}
\hline Variable & $\mathbf{U}$ & SD & D & $\mathbf{A}$ & SA & Mean & S. Dev. \\
\hline $\begin{array}{l}\text { Suspension from } \\
\text { school }\end{array}$ & $186(53.1)$ & $67(19.1)$ & $34(9.7)$ & $34(9.7)$ & $29(8.3)$ & 2.01 & 1.330 \\
\hline Motor accidents & $181(51.7)$ & $69(19.7)$ & $26(7.4)$ & $41(11.7)$ & $33(9.4)$ & 2.07 & 1.381 \\
\hline $\begin{array}{l}\text { Fighting with a } \\
\text { friend }\end{array}$ & $125(35.7)$ & $90(25.7)$ & $34(9.7)$ & $53(15.1)$ & $48(13.7)$ & 2.45 & 1.447 \\
\hline $\begin{array}{l}\text { Use of bad } \\
\text { language }\end{array}$ & $119(34.0)$ & $77(22.0)$ & $31(8.9)$ & $63(18.0)$ & $60(17.1)$ & 2.62 & 1.520 \\
\hline Accidents & $127(36.3)$ & $89(25.4)$ & $39(11.1)$ & $48(13.7)$ & $47(13.4)$ & 2.43 & 1.434 \\
\hline Sexual temptation & $125(35.7)$ & $88(25.1)$ & $32(9.1)$ & $54(15.4)$ & $51(14.6)$ & 2.48 & 1.467 \\
\hline $\begin{array}{l}\text { Poor school } \\
\text { performance }\end{array}$ & $137(39.1)$ & $82(23.4)$ & $42(12.0)$ & $48(13.7)$ & $41(11.7)$ & 2.35 & 1.412 \\
\hline Sickness & $123(35.1)$ & $93(26.6)$ & $32(9.1)$ & $49(14.0)$ & $53(15.1)$ & 2.47 & 1.465 \\
\hline $\begin{array}{l}\text { Absenteeism } \\
\text { school/work }\end{array}$ & $122(34.9)$ & $87(24.9)$ & $37(10.6)$ & $59(16.9)$ & $45(12.9)$ & 2.48 & 1.436 \\
\hline Skipping lessons & $131(37.4)$ & $94(26.9)$ & $38(10.9)$ & $42(12.0)$ & $45(12.9)$ & 2.36 & 1.413 \\
\hline Punishment & $139(39.7)$ & $90(25.7)$ & $38(10.9)$ & $47(13.4)$ & $36(10.3)$ & 2.29 & 1.375 \\
\hline
\end{tabular}

\section{Interventions for Alcohol Abuse}

The sixth and also the last research question sought to find out some of the interventions that can be provided to remediate the use of alcohol among the youth. The findings as presented in table 7 indicate that many of the respondents, 56.6\% (198) with a mean of 4.30 and standard deviation of 1.048, strongly agreed that the youth should be involved in alcohol intervention programmes. Also, an equal 
number of respondents, $42.3 \%$ (148), representing a mean response of 4.11 and a standard deviation of 1.057; both agreed and strongly agreed alcohol abusers must be punished. With a mean and standard deviation of 4.38 and 0.864 respectively, the majority of the respondents strongly agreed that laws must be enforced on the sale of alcohol especially when selling it to under-aged persons. The use of peer educators as a mean of sensitizing the youth on the need to avoid alcohol consumption was strongly agreed by 58.6\% (205) of the respondents, which had a mean of 4.47 and a standard deviation of 0.785 . Lastly, it was strongly agreed by the majority, two hundred and five representing $58.6 \%$ that there should be no advertisement on alcoholic products on both radio and television before 9:00 pm.

\section{Table 7- Interventions for Alcohol}

Frequency (Percentage)

\begin{tabular}{|l|l|l|l|l|l|l|l|}
\hline Variable & $\mathbf{U}$ & SD & D & A & SA & Mean & S. Dev. \\
\hline $\begin{array}{l}\text { Involvement in } \\
\text { intervention Prog }\end{array}$ & $13(3.7)$ & $22(6.3)$ & $11(3.1)$ & $106(30.3)$ & $198(56.6)$ & 4.30 & 1.048 \\
\hline $\begin{array}{l}\text { Punish alcohol } \\
\text { abusers }\end{array}$ & $12(3.4)$ & $32(9.1)$ & $10(2.9)$ & $148(42.3)$ & $148(42.3)$ & 4.11 & 1.057 \\
\hline $\begin{array}{l}\text { Enforcement of laws } \\
\text { on sale }\end{array}$ & $3(0.9)$ & $21(6.0)$ & $8(2.3)$ & $126(36.0)$ & $192(54.9)$ & 4.38 & 0.864 \\
\hline Peer educators & $6(1.7)$ & $7(2.0)$ & $7(2.0)$ & $125(35.7)$ & $205(58.6)$ & 4.47 & 0.785 \\
\hline $\begin{array}{l}\text { No advert before } \\
\text { 9:00 pm }\end{array}$ & $14(4.0)$ & $27(7.7)$ & $13(3.7)$ & $111(31.7)$ & $185(52.9)$ & 4.22 & 1.091 \\
\hline
\end{tabular}

\section{Discussion}

The finding of the first research question of this current study is contradictory to the finding of previous studies on alcohol use by the youth [1, 18, 19]. For instance, a study on the pattern of alcohol consumption among the youth in Bhaktapur, Nepal, reported an overall percentage of 56 of the youth engaged in drinking alcohol [19] as opposed to an overall percentage of about 32 of the youth in this study. Although, both this and the previous studies [1,18,19] used a descriptive cross-sectional research design, these differences in the findings of the levels of alcohol use among the youth in these two studies could be attributed to the different cultural backgrounds of the respondents. The findings of this study are synonymous to the previous study which reported that alcohol can cause a spectrum of untoward structural and functional changes in the brain and that changes to the brain associated with alcohol intake are regionally specific and can affect both gray and white matter; some of these changes are reversible with abstinence[20]. This indication reveals that the respondents in the present study are knowledgeable about associated brain damage as a result of alcohol consumption. It was found in a similar study that alcohol shows a dose-response relationship, where the risk of the onset of or death from the disease or condition depends on the total volume of alcohol consumed for the following conditions: cancer of the mouth, oesophagus, liver, and stomach [21]. Also, a related descriptive crosssectional study conducted on alcohol knowledge and consumption revealed that about $46.6 \%$ of the youth recognized that alcohol was a risk factor for cancer. In the same study, the majority of the youth representing 89.2\% were aware that alcohol consumption can cause liver cirrhosis [22]. These 
corroborate with the finding of this study as many of the respondents are knowledgeable about some of these adverse health effects of alcohol consumption.

The present finding somewhat correspond to the finding of a study on optimization of the sorghum malting process for pito production in Ghana which stated that almost half (44.7\%) of the respondents drink beer most [23] which is marginally higher than reported in a study carried out among senior high students in the Ga Central Municipality showed that 44.5\% consumed beer [1]. This synonymy can be attributed to the lower percentages of alcohol in beers and are more appealing to many people who do not want to be heavily drunk.

Youth exposure to alcohol advertising helps create an environment that suggests that alcohol consumption and overconsumption are normal activities and this contributes to increased alcohol consumption has a linkage with the finding of the present study. This study made a similar finding that advertisement for alcoholic products has the tendency of influencing about $44.0 \%$ to use those products. Though a previous study finding reported a lower percentage (20.3\%) on the use of advertisement [24] than the current study, it suggests that advertisements play a vital role in youth alcohol use patterns. Also, the findings of the studies on the risk factors and consequences of alcohol consumption among college students[25], and that on prevalence of alcohol consumption and factors influencing alcohol use among the youth in Tokorni-Hohoe, Volta Region of Ghana [24] correspond to the finding of this study as was found that peer pressure or introduction by friends to alcohol mostly get the youth to drink alcoholic beverages.

The findings of this study do not correspond with the findings revealed in the abnormal psychology: an integrate approach that psychotic disorders, persistent dementia, mood disorders and sexual dysfunction are alcohol-related induced disorders [26]. As stated in this study, many of the respondents were uncertain about some consequences of alcohol such as poor school performance and sickness. This can be interpreted to mean that some of these respondents might have ever suffered from some of the consequences but cannot be directly related to alcohol use. Also, the finding of alcohol, drugs and road traffic crashes in India: a systematic review [27] that a significant proportion of injured or killed road users in India had used alcohol before the accident contradict the finding of this study as many of the respondents reported of uncertainty about such occurrences. A lot of factors such as faulty automobiles, bad roads, tiredness, etc. can lead to accidents on the road and hence cannot be said to solely rely on alcohol use.

As found in this study, many were of the view that the youth should be involved in alcohol intervention programmes, however, there exists some synonymy between this study and previous similar studies which found a significant reduction in alcohol consumption as a result of brief interventions $[28,29]$.

\section{Conclusions}

The majority of the youth in New Edubiase do not use alcoholic beverages. This means that the level of use of alcohol among the youth is not rampant and frequent. Averagely, about $80 \%$ of the youth in New Edubiasepossess good knowledge about alcoholic products and the effects that they can have on the health of alcohol users. Such a high exhibition of knowledge about alcohol could be due to the efforts of 
health care professionals in educating the masses about the health implications of alcohol use. Beers are the most used alcoholic beverages among the minority of the youth in New Edubiase who reported to use alcohol. The major source of information about alcoholic products is television. The youth are mostly influenced to drink alcoholic beverages through peer pressure. Although some of them might have faced some of these problems, they might not necessarily result from the use of alcohol. There is a need to provide interventions on the use of alcohol. With the provision of interventions, alcohol use among the youth can be brought to the lowest possible minimum.

\section{Declarations}

\section{Acknowledgements}

We are grateful to the District Chief Executive, District Health Director, the assembly members, parents/ guardians, other opinion leaders and the youth of the study area. We thank various writers from whom references were made. We would like to thank all other individuals who provided the needed support for me to complete this study.

\section{Ethics approval and consent to participate}

Permissions were obtained from the District Chief Executive, District Health Directorate, the assembly members, parents/ guardians, other opinion leaders and the youth before the commencement of the study. Confidentiality, privacy and anonymity were also assured.

\section{Reference}

1. Annor J, Alcohol use among senior high school students in the Ga Central Municipality. School of Public Health, University of Ghana, 2016.

2. Pinsky I, Sanches M, Zaleski M, Laranjeira R, Caetano R,. Patterns of alcohol use among Brazilian adolescents. Revista Brasileira de Psiquiatria, 2010; 32(3), 242-249.

3. Chun TH, Linakis JG. Interventions for adolescent alcohol use. Current Opinion in Pediatrics, 2012; 24(2), 238-42.

4. World Health Organization. Global status report on alcohol. Author, 2011.

5. Ghana National Alcohol Policy. Ghana National Alcohol Policy. Ministry of Health, 2016, 6(2), 103.

6. Latendresse S J, Rose R J, Viken R J, Pulkkinen L, Kaprio J, Dick D M. Examining the etiology of associations between perceived parenting and adolescents' alcohol use: Common genetic and/or environmental liabilities? Journal of Studies on Alcohol and Drugs, 2010;71 (3), 313-2.

7. Oppong-Asante K, Meyer-Weitz A, Petersen I. Substance use and risk sexual behaviours among street connected children and youth in Accra, Ghana. Substance Abuse Treatment, Prevention, and Policy, 2014; 9(1), 45.

8. Díaz-Anzaldúa A, Díaz-Martínez A, Díaz-Martínez LR. The complex interplay of genetics, epigenetics, and environment in the predisposition to alcohol dependence. Salud Mental, 2011 34(2), 157-166. 
9. David Doku., Leena Koivusilta., \& Arja Rimpelä. (2012). Socioeconomic differences in alcohol and drug use among Ghanaian adolescents. Addictive Behaviors, 37(3), 357- 60. https://doi.org/10.1016/j.addbeh.2011.11.020

10. Coffie C N. Prevalence of substance use among Junior High School students. School of Public Health, Department of Social and Behavioral Science, University of Ghana. 2010.

11. Rehm J. The risks associated with alcohol use and alcoholism. PubMed, 2011; 34(2), 135-143.

12. Global Alcohol Policy Alliance. The Globe. Global Alcohol Policy Alliance, 2014.

13. Hiremath P, Vaishali RM, Prakash NSP, Anagha K. Descriptive study to assess the knowledge and attitudes on the effects of alcohol among nursing students in selected college at Karad. International Journal of Innovative Research and Development, 2016); 5(5), 133-136.

14. World Health Organization. Global status report on alcohol. Author, 2016.

15. World Health Organization. Global status report on alcohol. Author, 2013.

16. Derry DJ. The prevalence of alcohol use among road users and its impact on traffic crash severity in Ghana. Centre for Accident Research \& Road Safety. Queensland School of Psychology and Counselling. Faculty of Health, Queensland University of Technology Brisbane, Australia. Unpublished, 2017.

17. Dakubo C. Consumption and impacts of local brewed alcohol (akpeteshie) in the Upper West Region of Ghana: A public health tragedy. Social Science and Medicine, 2013; 57(9), 1747-1760.

18. Adjei ME. Substance use among students of a second cycle institution in Accra. Department of Social and Behavioural Science, School of Public Health, University of Ghana. Unpublished, 2016.

19. Purna LM, Kripa TM. Patterns of alcohol consumption among the youth of Bhaktapur, Nepal (Paperback). Wales, Lambert Academic Publishing, 2017.

20. Zahr NM, Kaufman KL, Harper CG. Clinical and pathological features of alcohol-related brain damage. Nature Reviews Neurology, 2011; 7, 284-294.

21. Shield KD, Parry C, Rehm J. Chronic diseases and conditions related to alcohol use. Alcohol Research Current Reviews, 2014; 35(2), 155- 171.

22. Kofoworola O, Babajide O, Folu O. Alcohol knowledge and consumption among medical students in Lagos. Universal Journal of Public Health, 2014; 2(4), 131-136.

23. Djameh C, Saalia F, Sinayobye E, Budu A, Essilfie G, Mensah-BrownH, Sefa-Dedeh S. Optimization of the sorghum malting process for pito production in Ghana. Journal of the Institute of Brewing, 2015; 121(1), 106-112.

24. Osei-Bonsu E. Prevalence of alcohol consumption and factors influencing alcohol use among the youth in Tokorni-Hohoe, Volta Region of Ghana. Science Journal of Public Health, 2017; 5(3), 205.

25. Kundapur R, Arjun SP, Arjun N, Arushi C, AvinashS, Chilsia S, Kiran H, Ravi K. Risk factors and consequences of alcohol consumption among college students. Department of Community Medicine, K.S. Hegde Medical Academy, Nitte University, Deralakatte, Mangalore, Karnataka, India, 2014.

26. Barlow DH, Durand VM. Abnormal psychology: An integrative approach (6 ${ }^{\text {th }}$ ed.). Toronto: Nelson Education, 2017.

27. Das A, Gjerde H, Gopalan SS, Normann PT. Alcohol, drugs, and road traffic crashes in India: A systematic review. Traffic Injury Prevention, 2012; 13(6), 544-53. 
28. Bernstein SL, D'Onofrio G, Fiellin DA, Pantalon VM, Chawarski MC, Owens PH, Degutis LC, Busch HS, O'Connor GP. A brief intervention reduces hazardous and harmful drinking in emergency department patients. Society for Academic Emergency Medicine. Phoenix, AZ, 2010.

29. Walton MA, Chermack ST, Shope JT, Bingham CR, Zimmerman M A, Blow FC, Cunningham RM. Effects of a brief intervention for reducing violence and alcohol misuse among adolescents: A randomized controlled trial. Journal of the American Medical Association, 2010; 304(5), 527-35. https://jamanetwork.com/journals/jama/fullarticle/186340

How to cite this Article: *Christiana Asiedu, Factors Contributing to Alcoholism Among the Youth in New Edubiase of Adansi South District in Ashanti Region-Ghana

Int. Res. Med. Health Sci., 2019; (2-5): 28-43

Source of Support: Nil, Conflict of Interest: None declared. 